\title{
A vida parada, uma vida ainda: o pensamento pictórico e a inauguração estético-política da modernidade
}

\author{
The still life, the life still: pictorial thinking \\ and the aesthetic-political inauguration of modernity
}

\author{
Eduardo Passos; Danichi Hausen Mizoguchi \\ Universidade Federal Fluminense
}

\begin{abstract}
RESUMO:
O presente artigo enfatiza as ligações entre campos aqui considerados distintos e inseparáveis: a estética e a política. Interessa-nos problematizar os múltiplos jogos entre a governamentalidade e alguns modos pictóricos que aparecem entre os séculos XVI e $X X$. Sabe-se que o regime de poder moderno se faz sob jogos de visibilidade que observam a vida em toda sua minúcia vã. Este gesto político terá como correlato estético a natureza-morta barroca. Mas os encontros entre a política e a arte se dão sob variadas modulações, as quais se fazem também como resistência ao poder na experiência da pintura moderna nos séculos XIX e XX. Parece-nos ser justamente nesta interface estético-política - notadamente quando ela se faz força de criação artística e subjetiva que é preciso pensar para que não caiamos na imobilidade ética a que o regime de condução das existências no presente pode nos levar.
\end{abstract}

Palavras-chave: política; estética; pintura

\begin{abstract}
:
This article emphasizes the links between fields considered here to be distinct and inseparable: aesthetics and politics. We are interested in problematizing the multiple games between governmentality and some pictorial modes that appear between the 16th and 20th centuries. It is known that the modern power regime is made under games of visibility that observe life in all its vain minutiae. This political gesture will have Baroque still life as an aesthetic correlate. But the encounters between politics and art take place under various modulations, which also take place as resistance to power in the experience of modern painting in the 19th and 20th centuries. It seems to us that it is precisely in this aesthetic-political interface - notably when it becomes a force for artistic and subjective creation - that it is necessary to think so that we do not fall into the ethical immobility that the regime of conducting existences in the present can lead us to.
\end{abstract}

Key-words: politics; aesthetics; painting.

DOI: 10.12957/mnemosine.2020.57657

\section{Introdução}

A intenção deste texto é enfatizar as ligações entre campos que entendemos como distintos e inseparáveis: a estética e a política. Nessa relação ampla de distinção e 
inseparabilidade, interessa-nos problematizar especificamente os múltiplos jogos entre o que Michel Foucault chamou de governamentalidade e alguns modos pictóricos que aparecem na pintura entre os séculos XVI e XX. Se o regime microfísico de poder moderno se faz sob jogos de visibilidade que observam a vida em toda sua minúcia vã, o grande espelho estético deste modo político é a natureza-morta barroca e seu gesto artístico de parar a vida em um still pictórico.

Mas, se afirmamos que há jogos estético-políticos, é porque entendemos que os encontros entre a política e a arte se dão sob variadas modulações, as quais se fazem também como resistência ao poder na experiência da pintura moderna nos séculos XIX e XX. Parece-nos ser justamente nesta interface estético-política - notadamente quando ela se faz força de criação artística e subjetiva - que é preciso pensar para que não caiamos na imobilidade ética a que o regime de condução das existências no presente pode nos levar.

\section{A governamentalidade e a visibilidade moderna: a vida parada}

No curso Segurança, território, população, ministrado no Collège de France entre 1977 e 1978, Michel Foucault propõe um novo conceito no decurso de suas pesquisas: a governamentalidade. Foucault destaca que entre os séculos XVI e XVIII desenvolveu-se uma série de tratados sobre a arte de governar, pondo em contraste duas tecnologias do poder distintas. Trata-se da passagem da sociedade marcada pelo poder soberano para a sociedade disciplinar. No primeiro diagrama de poder, há um modo de governar caracterizado pela exterioridade e pela transcendência do príncipe em relação ao seu principado. O príncipe é aquele que recebe um território por herança, por aquisição ou por conquista, mas não faz parte deste mesmo território: seus laços são estabelecidos ou por tratados ou por violência. A relação é, portanto, frágil e constantemente ameaçada pelos inimigos, que tentarão conquistar o principado. O objetivo do exercício do poder é, consequentemente, o de "reforçar e proteger este principado, entendido não como o conjunto constituído pelos súditos e o território, (...) mas como [a] relação do príncipe com o que ele possui" (FOUCAULT, 1979: 279). A teoria jurídica do soberano demarcase pelo poder de espada: o soberano fazia aparecer seu poder na medida em que podia ostentar o poder de matar. Era aquilo que Foucault enunciou sob uma fórmula tão simples quanto precisa: deixar viver e fazer morrer. 
Outro diagrama se apresenta como arte de governar que, no século XVI, começa a tomar como alvo, inusitadamente, não só corpos a serem docilizados nas instituições disciplinares, mas a relação dos homens com um conjunto diverso de coisas. Duas artes de governança, duas estratégias de poder, dois diagramas de relações de forças que se distinguem pelo ponto de sua incidência, isto é, sobre o que se exerce e como se exerce o poder. A transcendência e a uniformidade do poder político soberano são substituídas pela multiplicidade dos exercícios de poder e pela sua imanência nos diferentes objetos ou coisas governadas. Eis que a modernidade se apresenta como nova topologia política, pois entre o foco de emanação do poder e seu ponto de incidência não há mais a distância que caracterizava o exercício do poder soberano.

Governar a nação, governar a família e governar a si mesmo são, doravante, exercícios que se realizam num mesmo plano de imanência do político: o plano da vida. Estamos submetidos, doravante, a uma tecnologia de poder que "opera sobre o campo de possibilidade onde se inscreve o comportamento dos sujeitos ativos; ele incita, induz, desvia, facilita ou torna mais difícil, amplia ou limita, torna mais ou menos provável" (FOUCAULT, 2013a: 243). Trata-se, em suma, de uma ação sobre ações. A fórmula, novamente tão simples quanto precisa, agora é invertida: fazer viver e deixar morrer. Junto à nova incidência do poder, toda uma nova visibilidade se anuncia no século XVI. A modernidade é também uma questão ótica. Algumas páginas preciosas de Vigiar $e$ punir (FOUCAULT, 1987: 144) atestam a importância desta espécie de viragem perceptiva no diagrama do poder moderno:

(...) da grande tecnologia dos óculos, das lentes, dos feixes luminosos, unida à fundação da física e da cosmologia novas, houve as pequenas técnicas das vigilâncias múltiplas e entrecruzadas, dos olhares que devem ver sem ser vistos; uma arte obscura da luze do visivel preparou em surdina um saber novo sobre o homem, através das técnicas para sujeitá-lo e processos para utilizá-lo.

Não à toa, no famoso panóptico inventado por Jeremy Bentham "inverte-se o princípio da masmorra; a luz e o olhar de um vigia captam melhor que o escuro que, no fundo, protegia" (FOUCAULT, 1979: 210).

É justamente a relação entre um novo regime de governo e uma nova forma de visibilidade que queremos tomar como centro para a discussão estético-política. A arte moderna de governar impõe uma alteração na tecnologia de poder que corresponde, nas artes plásticas, a uma mudança do regime de visualidade e sensibilidade que permite o aparecimento de uma forma pictórica nova: a natureza-morta. Esse termo, que é formulado tardiamente no século XVIII, designa a retratação de objetos inanimados que 
começam a ocupar o olhar dos artistas no mesmo século XVI em que as artes de governar aparecem. A expressão latina "natureza-morta" é uma tradução da palavra holandesa still leven, que em inglês se diz still live: vida parada. É justamente o contrassenso da expressão que reúne em um só vocábulo dois termos contrastantes - natureza e morte ou vida e imobilidade - que nos instiga a pensar tal regime de visibilidade na sintonia do encontro entre a política e a estética.

Se é verdade que o Renascimento italiano criou as condições para que a "coisa natural" pudesse ocupar uma posição de destaque na arte, é somente no barroco que ela ganha sua dignidade de tema artístico, deixando de ser tratada exclusivamente como símbolo ou alegoria. Tomando de empréstimo a expressão de Patrícia Guimarães (1998), já no Renascimento o regime de sensibilidade se altera com a "dignificação do objeto", embora a coisa se apresente, nesse início da modernidade, através de uma arte do sujeito: "O objeto é categoria que só adquire significação com relação ao humano" (GUIMARÃES, 1998: 20). A “coisa" acaba por se apresentar como realidade natural e significativa em si somente sob a ótica naturalista do barroco, e a natureza-morta é o tema pictórico desta "dignificação da coisa" independente da presença do sujeito retratado. "Elevado à condição de tema autônomo, o objeto, mero detalhe do mundo visível, é transposto à condição de todo significativo na arte. E adquire potencialidade expressiva, tornando-se apto a veicular, por si só, a intenção subjetiva do artista" (GUIMARÃES, 1998: 24).

A arte barroca é a estética da imagem per si. A figura não se define mais por sua função simbólica ou alegórica. A imagem artística alude, a partir do barroco, à coisa retratada por ela mesma: a imagem do peixe é simplesmente um peixe - justo uma imagem e não uma imagem justa, como diria Jean-Luc Godard. A justeza desta imagem estabelece uma forma de comunicação em que é a coisa ela mesma que fala em sua “eloquência calada". Esta é a expressão que Hans-Georg Gadamer (1988: 123-134) utiliza para designar a "impressão de emudecimento" na arte que se inaugura com a naturezamorta no século XVI, pois a imagem passa a não admitir outra comunicação que não a da sua visualidade. A obra não se define a partir do que pode se interpretar, como um subtexto em que reside o sentido discursivo a ser decifrado: é a coisa que diz de si, havendo, portanto, uma força de enunciação em seu silêncio de imagem que é a sua própria eloquência. 
E se há na natureza-morta barroca uma distinção entre o visível e o invisível, é de uma falsa dicotomia que se trata. Entre o aparente e o que se oculta, é o invisível da força que comparece no quadro fazendo a torção das formas, num gesto poiético de revelar a gênese do que há. Esta é a tese defendida por Deleuze em seu livro Leibniz e o barroco (2012), em que apresenta o barroco como uma função operatória da "dobra que vai ao infinito" (p. 13), expressando "as potências de alargamento e de estiramento do mundo" (p. 188). Na natureza-morta, esta operação infinita realiza a elevação das coisas finitas que se tornam a ocasião para mostrar este princípio de criação da matéria operando no mais singelo e vão dos objetos: "roupagens fazendo dobras de ar ou de nuvens pesadas; toalha de mesa com dobras marítimas ou fluviais; ourivesaria ardendo em dobras de fogo; legumes, cogumelos ou frutos confeitados são captados em suas dobras da terra" (DELEUZE, 2012: 185). Em suma, a força do ínfimo, a força no ínfimo.

É este o ensejo para o tema barroco das vanidades na natureza-morta: pintar o que é vão é estar alheio às transcendências e ligado às concretudes, mas é também buscar o que há de infinito na finitude - a imagem do crânio, a bolha de sabão, a borboleta, a flor, a fumaça do tabaco, a fruta, os restos da refeição sobre a mesa. Uma vida parada em sua vanidade mais ínfima: é isso que é retratado sob o foco desta nova visualidade que se inaugura quase que simultaneamente à arte de governar moderna. E, no absurdo da expressão "vida parada" ou "natureza morta", o pensamento pictórico leva, ao infinito ínfimo das coisas, a tentativa da apreensão definitiva do seu sentido. No quadro barroco, o artista parece zombar da pretensão moderna de ter a visão clara e distinta das coisas, de se assegurar como o cogito inquestionável porque enunciado justo sobre o que existe. A tentativa de visibilização panóptica do mundo é submetida, no enquadre da natureza morta barroca, à operação de reductio ad absurdum do regime de luz da nova governamentalidade: se é para tudo por à vista, resta-nos então apenas a vanidade.

O que queremos destacar é esta sintonia entre a tecnologia de poder na arte de governar as coisas e a estética barroca. Ver as coisas, governar as coisas, pintar as coisas: poder sobre a vida, vida parada. A visão das coisas e o exercício de governo sobre elas se faz, doravante, com uma incidência capilar, microfísica, e que vai focando a vida em sua vanidade. E o perigo deste jogo visual que nos aproxima das coisas com um interesse míope é o da paralisia da vida: o encantamento de uma natureza-morta como paradigma de governo.

Mas a sintonia entre o jogo político e o jogo estético não deve ser tomada como estanque. Ao contrário, é nesse jogo estético-político que devemos tentar operar 
processos de resistência - tanto mais difícil quanto sofisticada é a mirada do poder. E, para tanto, talvez se insinue um estranho jogo retórico-político em que o adjetivo se torna advérbio. Se still em inglês significa parado, também pode ser um advérbio de tempo: ainda. Still life não sendo mais a vida parada, mas, doravante, uma "vida ainda" - ainda a vida, com tudo o que ela opera de conexão com o fora, com o movimento, com a alterização. É no paradoxo do still life - vida parada e uma vida ainda - que talvez devamos agora nos colocar eticamente para pensarmos o vetor de resistência junto às perspectivas estético-políticas dos jogos do poder moderno.

\section{A verdade e a pintura: entre a representação e a criação}

Entendemos, portanto, que há não só uma relação estética, mas também ética entre a governamentalidade e o barroco. A governamentalidade operava uma modulação diagramática de poder a qual, se fazendo imanente ao campo social, tratava de governar as coisas - e, no limite, governar a vida em toda sua minúcia. A estética barroca, sob a fundação paradoxal das imagens da natureza-morta, mostrava as forças dobrando aquilo que era supostamente vão. Governo da vida, vida parada foi a fórmula que encontramos para melhor expressar essa espécie estranha de sintonia microfísica entre a política e a arte no século XVI.

Sob a modificação de status do still life - da vida parada à vida ainda -, tentaremos expor outras imagens pictóricas a fim de forçar a passagem da relação entre a política e a estética que tanto nos interessa. Para tanto, operaremos a análise daquilo que talvez possamos chamar de um pensamento pictural, sobrevoando alguns movimentos artísticos realizados a partir do final do século XIX. Todavia, para que esse jogo político-estético apareça é preciso antes coligá-lo a um jogo que é filosófico.

Desta perspectiva filosófica que de início nos interessa, deve-se de saída dizer que ela talvez tenha certo atributo de definição que queremos aqui recolocar sob a disputa de sentido. Entre 1970 e 1971, no primeiro curso que ministra no Collège de France, intitulado A vontade de saber, Michel Foucault conduz-se sob uma intriga basal. Nos termos usados na ocasião, o jogo que Foucault (2014: 4) gostaria de jogar

(...) consistiria em saber se a vontade de verdade não é tão profundamente histórica quanto qualquer outro sistema de exclusão; se, na raiz, não é arbitrária como eles; se não é modificável como eles no decurso da história; se, como eles, não se apoia e, como eles, não é incessantemente reativada por toda uma rede institucional; se não forma um sistema de coerção que se exerce não só sobre outros discursos mas sobre toda uma série de outras práticas. 
Em suma, o que interessa para Foucault é afirmar que a distinção mesma entre o verdadeiro e o falso é política e histórica. Sua posição é categórica ao defender que o fato de vivermos em um mundo cindido pelo verdadeiro e pelo falso já é uma coerção delicada e poderosa.

É em Aristóteles que Foucault encontra a gênese desta cisão que ele entende como fundamental - fundamental para a história da filosofia, certamente, mas também para todo argumento estético e político que aqui defendemos. Trata-se da colocação do "jogo da verdade na rede de coerções e de dominações" (FOUCAULT, 2014: 6). Isto porque Aristóteles designa a si mesmo a tarefa de deliberar com clareza o que é e o que não é a filosofia - e, ato contínuo, de definir as relações precisas e específicas entre a filosofia e a verdade. Este movimento ocorre especialmente quando o estagirita, em sua Metafísica, apresenta aquilo que chama de um "acesso ao verdadeiro - às coisas em si mesmas, em suas qualidades próprias" [e de um] "conhecimento do verdadeiro em si mesmo" (FOUCAULT, 2014: 21): esse acesso e esse conhecimento do verdadeiro em si caracterizariam exatamente as peculiaridades exclusivas e meritórias da filosofia - são suas qualidades, no duplo sentido da palavra.

É no pensamento aristotélico que a operação filosófica passa a dar a si mesma a tarefa de dizer a verdade do mundo. É com ele que a filosofia se torna o modo verdadeiro de enunciação para um mundo que verdadeiramente é. Essa relação de dupla estabilidade - a verdade e o mundo, o logos e a physis, a palavra e a natureza - torna-se a especificidade da filosofia, e é esta, sobremaneira, a sua tarefa: enunciar a verdade de um mundo que verdadeiramente é.

Teoria - do grego theorein - significa ver: ter a visão de algo situado na natureza ou no mundo. Fazer teoria é fazer ver a inteligibilidade conceitual do cosmo. Assim, nessa relação entre as imagens, as palavras e as coisas, pintar é também teorizar. A tarefa de mostrar a verdade do mundo pode ser, portanto, também uma tarefa artística: no correlato artístico daquilo que Aristóteles definia como a tarefa da filosofia, fazer arte é representar com exatidão o mundo que é. Exemplos não faltariam, mas basta dizer que não é outra a tarefa barroca: representar com perfeição as forças do mundo dobradas na minúcia das vanidades.

A importância do Impressionismo em uma outra teoria da visualidade - aquela que nos levará a uma vida ainda -, é antecipada pelas inovações realizadas por Édouard 
Manet. É assim que Foucault (2011: 260) diz em conferência ministrada na Tunísia em 1971:

Manet figura sempre, na história da arte, na história da pintura do século XIX, como aquele, evidentemente, que modificou as técnicas e os modos de representação pictórica, de maneira tal que ele tornou possível esse movimento do impressionismo que ocupou a frente da cena da história da arte durante quase toda a segunda metade do século XIX.

Em Manet, um quadro é um quadro e não a imitação da vida - o que é sua limitação, mas também sua liberdade. Nos termos de Foucault, Manet inventa "o quadroobjeto, o quadro como materialidade" (FOUCAULT, 2011: 262). Esse gesto pictórico de Manet não buscava a mimese - o que é importante para quase todas as experiências artísticas do século XX e XXI que vão na contracorrente da perspectiva filosófica aristotélica: a inserção da materialidade da tela naquilo que é pintado é um dos cernes da modificação trazida por Manet às artes plásticas.

E talvez o gesto fundamental de Manet se encontre em um quadro chamado "Un bar aux Folies-Bergère”, de 1882. É nele que aparece um estranhíssimo espectador móvel: trata-se de um quadro com pelo menos dois pontos de vista, em que o jogo de espelhos faz com que aquele que observa a pintura suponha o pintor - e a si mesmo - em pelo menos dois lugares. E Manet não escolhe subtrair ou sobrepor os dois: ele os faz aparecer como dois pontos de vista legítimos e possíveis em sua simultaneidade. Neste quadro curiosíssimo talvez reste um delicado recado à filosofia: não há verdade que não seja um ponto de vista - e todo ponto de vista é a vista de um ponto dentre muitos pontos legítimos.

Haveria, no pensamento pictórico - ou na teoria - exposto por Manet, a possibilidade de que diferentes perspectivas sejam postas lado a lado. O jogo de visualidade convocado por Manet, portanto, é aquele que não aposta nas conjunções alternativas da verdade como representação de um único mundo possível, mas nas conjunções alternativas das localizações que multiplicam mundos. Parece ser exatamente assim que uma série de genealogias distintas do capitalismo - todas elas politicamente muito contundentes - tem podido aparecer, com histórias cujas localizações e narrativas múltiplas interrompem a indicação de que o nascimento único do sistema econômicosubjetivo maior de nossos tempos tenha ocorrido exclusivamente com a acumulação primitiva de capital. Bastaria lembrar o trabalho de Silvia Federici, que em Calibã e a bruxa (2017) indica que há algo que só pode acontecer a partir do cercamento do corpo 
feminino e do fogo ateado naquelas que escapam do destino de máquina de trabalho reprodutivo. Ao lado dessa perspectiva feminista - e não contra ela -, as indicações de Achille Mbembe em Crítica da razão negra (2018) demonstram arqueologicamente que a invenção da raça e do racismo é condição sine qua non para a expansão colonial e a economia da plantation, sem o que o capitalismo não se faria como se fez. Da mesma maneira, o livro recentemente lançado por Éric Alliez e Maurizio Lazzarato, Guerres et capital (2016), apresenta a importância da modulação de toda a política capitalista sob o paradigma da guerra, e, se quisermos, a História da loucura contada pelo próprio Foucault (1978), segundo a qual o jogo moderno é aquele que opera por cisões políticas tais quais a que se dá entre a razão e a desrazão.

Se Manet pôde mostrar que há mais de um ponto de vista para toda e qualquer cena ou análise - e que a multiplicidade de localizações pode instaurar diversas genealogias possíveis e, logo, diversos enfrentamentos políticos que se lateralizam -, os impressionistas trataram de extrapolar o jogo pictórico-filosófico proposto por ele: mais do que só haver pontos de vista, só o que há são impressões - todo ponto de vista é a impressão de um ponto de vista. Se até meados do século XIX o público estava acostumado a ver um quadro como se fosse um espelho no qual ele e seu mundo encontravam-se refletidos, com o Impressionismo vemos apenas impressões do mundo ou o mundo como impressão, forjando um processo estético de decomposição formal e molecularização que não era nem um pouco trivial.

Tanto esse processo de decomposição formal não era trivial que o termo impressionismo foi cunhado como um insulto. "Impressão... qualquer papel de parede é mais bem-acabado do que essa marinha", escreveu o crítico Louis Leroy ao observar o quadro inaugural do movimento, "Impressão, sol nascente", de Claude Monet, de 1872. Fato é que o Impressionismo tornou-se a técnica pictórica criada para melhor representar a cambiante impressão visual da realidade. Representar não a realidade do sol nascente, mas a sua impressão aos olhos do artista: representar a representação, dobra sobre si da perspectiva, visão da visão nesse exponencial que leva a representação para além de qualquer pretensão realista.

O Impressionismo retratava o não ser do ser - à moda heraclitiana de um mundo em devir. Assim como é impossível entrar no mesmo rio duas vezes, porque nem o rio nem nós somos mais os mesmos, é impossível pintar uma mesma paisagem duas vezes porque tudo é fluxo. Tratava-se, portanto, de pintar o informe e a transitoriedade das impressões do mundo. E como retratar essa verdade imagética do mundo - a verdade de 
um mundo cujas imagens não têm formas definitivas - senão pela velocidade da impressão cambiante, singular e irrepetível?

Talvez nada seja mais moderno do que a fugacidade do tempo - e para representar pictoricamente os momentos fugazes dos quais o mundo é feito, foi preciso decompor a forma. "Quero fixar um momento do movimento", é o que dizia Rodin. Isto acabava por dar às obras um aspecto de inacabamento para a sensibilidade do século XIX, acostumada ao apuro formal destruído intencionalmente pelos impressionistas.

No início do século XX, deram-se algumas radicalizações do procedimento de afastamento do realismo e de destruição das formas. Uma dessas radicalizações é o cubismo. "Les demoiselles d'Avignon”, quadro pintado por Pablo Picasso em 1907, talvez seja a obra que traçou os rumos do movimento, prefigurando a colagem e influenciando praticamente todos os outros movimentos artísticos do século XX. Isto porque os cubistas insistiam em que a arte não era uma cópia, mas um paralelo da natureza: na arte já não se tratava de imitação, mas de criação da vida.

Se Manet havia mostrado a possibilidade de uma obra pictórica na qual dois pontos de vista simultâneos apareciam, se os impressionistas haviam pintado um mundo sem forma, na fugacidade única e singular da sensibilidade irrepetível, com o cubismo tratava-se de decompor o mundo e retratá-lo como ele jamais havia sido: "Les demoiselles d'Avignon" mostra isso, radicalizando ainda mais do que em Manet a observação a partir de pontos de vista em movimento. Sob a influência da arte africana, o que aparece é um mundo absolutamente criado: formas inexistentes, ângulos múltiplos, perspectivas variadas, cores irreais. Em suma, a apresentação pictórica do célebre ensinamento nietzschiano: por trás de uma máscara não há um rosto, mas sempre outra máscara - neste caso, a máscara cerimonial da tribo Dogon.

Aparece, portanto, um mundo sem essência - passível de ser colado, composto, inventado. A natureza-morta já não é mais a vanidade microfísica da força: doravante é a colagem - como na "Natureza-morta sobre uma mesa: Gillette", de Georges Braque. Mostrar o mundo em sua minúcia, agora, era montar numa colagem o mundo em sua minúcia. Foucault já parece próximo ao dizer que "o homem moderno não é aquele que parte para descobrir a si mesmo, seus segredos e sua verdade escondida: é aquele que busca inventar-se a si mesmo" (FOUCAULT, 2006: 241). 
Traição das imagens é o quadro pintado por René Magritte em 1929 que Foucault tomará como emblema definitivo do fim da representação. Ceci n'est pas une pipe - que é o título que Foucault dá ao seu texto, cuja primeira versão é publicada meses depois da morte do pintor - é a frase inscrita no quadro em que aparece a imagem de um cachimbo. O quadro olha para o quadro indiferente ao que se imporia como o seu referente na realidade. Ali, a realidade é exclusivamente a da criação: pintar é trair a realidade. Isto é, o pintor, tal como um tradutor, trai o texto supostamente original: toda tradução é uma traição, para retomarmos a fórmula de Vittorio Imbriani, traduttore, traditore, que a utiliza pela primeira vez em 1869 - portanto três anos depois do quadro inaugural do Impressionismo.

\section{Considerações finais: uma vida ainda}

Em A força de fugir, Foucault (2010, p. 401) assim disse: “A pintura tem ao menos isto em comum com o discurso: quando ela transmite uma força que cria história, ela é política". Se entendemos todas essas experiências estéticas aqui brevemente apresentadas como experiências históricas e políticas, é porque achamos importante torná-las partícipes de movimentos que só podem ser entendidos como limiares - jamais puramente estéticos: são pensamentos pictóricos. É exatamente assim que Gilles Deleuze e Felix Guattari (1992, p. 43) anunciam: "É necessário experimentar em seus mínimos detalhes o vínculo único, exclusivo, dos conceitos com a filosofia como disciplina criadora". Com Deleuze e Guattari - e próximos a essas experiências estéticas advindas do século XIX e plenamente vivazes no século XX -, filosofar não é mais dizer a verdade de um mundo que verdadeiramente é: filosofar é criar conceitos, filosofar é criar um mundo. Experiência estética e experiência filosófica que fazem a vida subsistir, resistente e renitente, em um processo jamais estável de criação: finalmente, a estética e a filosofia de uma vida ainda.

Por ora, talvez devamos manter viva a inquietação de Foucault e, como ele, nos espantar. Foi assim que ele disse:

O que me surpreende é o fato de que, em nossa sociedade, a arte tenha se transformado em algo relacionado apenas a objetos e não a indivíduos ou à vida; que a arte seja algo especializado e ou feita por especialistas que são artistas. Entretanto, não poderia a vida de todos se transformar numa obra de arte? (FOUCAULT, 2013b: 306).

E se a vida feita obra de arte é aquela que dista o máximo possível da representação, talvez seja esta a tarefa restante: criar em si mesmo as possibilidades 
estéticas e políticas para que a vida não pare - para que a vida seja uma vida ainda e sempre.

\section{Referências}

ALLIEZ, Eric; LAZZARATO, Maurizio. Guerres et capital. Paris: Amsterdam, 2016.

DELEUZE, Gilles. Leibniz e o barroco. Campinas, SP: Papirus, 2012.

DELEUZE, Gilles; GUATTARI, Félix. O que é a filosofia? Rio de Janeiro: Ed. 34, 1992.

FEDERICI, Silvia. Calibã e a bruxa: mulheres, corpo e acumulação primitiva. São Paulo: Elefante, 2017.

FOUCAULT, Michel. História da loucura. São Paulo: Perspectiva, 1978.

FOUCAULT, Michel. A governamentalidade. Em: Microfisica do poder. Rio de Janeiro: Graal, 1979. p. 277-293.

FOUCAULT, Michel. Vigiar e punir: nascimento da prisão. Petrópolis: Vozes, 1987.

FOUCAULT, Michel. Resumo dos cursos do Collège de France (1970-1982). Rio de Janeiro: Jorge Zahar, 1997.

FOUCAULT, Michel. A psicologia de 1850 a 1950. Em: Problematização do sujeito: psicologia, psiquiatria e psicanálise. Rio de Janeiro: Forense Universitária, 2006. p. 133-151.

FOUCAULT, Michel. A força de fugir. Em: Repensar a política. Rio de Janeiro: Forense Universitária, 2010. p. 82-86.

FOUCAULT, Michel. A pintura de Manet. Visualidades, Goiânia, vol. 9, nº 1, p. 259285, jan-jun 2011.

FOUCAULT, Michel. O sujeito e o poder. Em: RABINOW, Paul; DREYFUS, Hubert. Michel Foucault: uma trajetória filosófica: para além do estruturalismo e da hermenêutica. Rio de Janeiro: Forense Universitária, 2013a. p. 231-249.

FOUCAULT, Michel. Sobre a genealogia da ética: um panorama do trabalho em curso. Em: RABINOW, Paul; DREYFUS, Hubert. Michel Foucault: uma trajetória filosófica: para além do estruturalismo e da hermenêutica. Rio de Janeiro: Forense Universitária, 2013b. p. 296-313.

FOUCAULT, Michel. Aulas sobre a vontade de saber: curso ministrado no Collège de France (1970-1971). São Paulo: Martins Fontes, 2014.

GADAMER, Hans-Georg. A imagem emudecida. Gávea: Revista de História da Arte e Arquitetura. Departamento de História da PUC, RJ, n. 6, 1988, p. 123-134.

GUIMARÃES, Patrícia. Natureza-morta. A representação do inanimado na pintura. Especialização em História da arte e arquitetura no Brasil. PUC-RJ, junho de 1998.

MBEMBE, Achille. Crítica da razão negra. São Paulo: n-1 edições, 2018. 
Eduardo Passos

Danichi Hausen Mizoguchi

Universidade Federal Fluminense, Instituto de Psicologia

E-mails: e.passos1956@gmail.com; danichihm@ hotmail.com 